\title{
Substratos orgânicos na produção de mudas de cafeeiro em tubetes
}

\author{
Igor Souza Pereira ${ }^{1}$, Karen Cristina Corrêa de Lima ${ }^{1}$, Heliomar Baleeiro de Melo Junior ${ }^{1}$ \\ ${ }^{1}$ Instituto Federal de Educação, Ciência e Tecnologia do Triângulo Mineiro, Campus Uberlândia, Uberlândia, Minas Gerais, Brasil. \\ E-mail: igor@iftm.edu.br, karencristina-c@hotmail.com, heliomarmelo@iftm.edu.br
}

Recebido: 15/09/2016; Aceito: 02/05/2017.

\section{RESUMO}

Considerando-se a importância das mudas na formação de lavoura cafeeira (Coffea arabica L.), objetivou-se avaliar características agronômicas e índices de qualidade de mudas do cafeeiro cv. Topázio MG 1190, produzidos em tubetes com a utilização de diferentes proporções de materiais orgânicos no substrato comercial. O experimento foi em delineamento experimental em blocos casualizados, dispostos em esquema fatorial $4 \mathrm{x} 4$, sendo quatro fontes de esterco: bovino, cama de frango, coelho e suíno em quatro proporções $(0,20,40$ e $60 \%)$ no substrato comercial Bioplant ${ }^{\circledR}$ com quatro repetições. As parcelas foram formadas por sete plantas dispostas em tubetes com volume de $180 \mathrm{~mL}$. Foram avaliadas as características agronômicas: altura da planta, número de par de folhas, área foliar, diâmetro de caule, massa seca da parte aérea, massa seca da raiz, relação altura da planta e diâmetro de caule, relação massa seca de parte aérea e massa seca da raiz e índice de qualidade de Dickson (IQD). Os resultados obtidos permitem concluir que o esterco de coelho até a dose de 32,7\% no substrato proporcionou maior desenvolvimento das mudas de café representado pelo IQD calculado em 1,31. A adição de cama de frango, esterco suíno e esterco bovino podem ser utilizados até as doses máximas de 25\%, 5,2\% e 17,4\% respectivamente. A partir dessas doses pode ocorrer uma rápida diminuição no IQD. Na dose de $60 \%$ de esterco suíno e esterco bovino foi observado morte de mudas.

Palavras-chave: Coffea arabica L., Índice de qualidade de Dickson, esterco

\section{Organic substrates in coffee seedling production in plastic tubes}

\begin{abstract}
Considering the importance of the seedlings in coffee (Coffea arabica $\mathrm{L}$ ) crop formation, the aim was evaluate the coffee seedlings features and quality indexes, cv Topázio MG 1190, produced in polyethylene tubes with commercial substrate supplemented with different proportions of organic materials. The experiment was carried out in randomized block design, in factorial scheme $4 \times 4$, the factors being four manure sources: cattle manure, poultry litter, pig manure and rabbit manure in four proportions $(0,20,40$ and $60 \%)$ in commercial substrate Bioplant ${ }^{\circledR}$. The plots were constituted by seven plants, in polyethylene tubes with volumetric capacity of $180 \mathrm{~mL}$. The following features were determined: shoot height, number of leaf pairs, leaf area, stem diameter, stem dry mass, root dry mass, plant height and stem diameter ratio, stem dry mass and root dry mass ratio and Dickson quality index (DQI). With the results was possible conclude that rabbits manure provided greater coffee seedlings development until maximum level of 32,7\%, in commercial substrate, represented by Dickson quality index calculated in 1,31 . The poultry litter, pig and cattle manure addiction could be used until the maximum levels of $25 \%, 5,2 \%$ and $17,4 \%$, respectively. From these levels, a rapid decrease in Dickson quality index can occur. Seedlings' death was observed with $60 \%$ levels of pig's manure and cattle manure.
\end{abstract}

Key words: Coffea arabica L., Dickson quality index, manure 


\section{Introdução}

A cafeicultura brasileira pode ser caracterizada como altamente tecnificada, de elevado status produtivo para os padrões internacionais; para tanto depende da renovação e adequação dos cafezais aos sistemas de plantio atuais (DARDENGO et al., 2013; MATIELLO et al., 2010). No Brasil, a área ocupada por esta cultura na safra 2016/2017 é de 2.228.194,7 hectares (ha), sendo que $272.786,5$ ha estão em formação, ou seja, tem sido elevada a demanda de mudas de cafeeiros para plantio dessas novas áreas (CONAB, 2017).

Portanto, a formação de mudas de café livres de doenças e capazes de resistir ao transplante é fundamental para se obter um stand homogêneo, com elevada produtividade e longevidade produtiva (COGO, et al. 2012; SILVA et al., 2013; BALIZA et al., 2013).

Vários fatores podem determinar o desenvolvimento, a qualidade e os custos para a produção de mudas, em que se destaca o tipo de recipiente, de substrato e nível de sombreamento (VALONE et al., 2010; DARDENGO et al., 2013; OLIVEIRA; MIGLIORANZA, 2015). Entre os recipientes que são utilizados na produção comercial de mudas de café destacam-se os tubetes e as sacolas de polietileno. A utilização de tubetes tem sido adotada em muitos viveiros, pois facilita o manuseio, requer menor área útil no viveiro, bem como a economia de substrato (DIAS; MELO, 2009). No entanto, obtêm-se mudas com índice de qualidade de Dickson (IQD) inferiores às produzidas em sacolas de polietileno (DARDENGO et al., 2013). O IQD é considerado um bom indicador da qualidade de mudas de café pois considera para o seu cálculo a robustez, representada pela matéria seca total e o equilíbrio da distribuição da fitomassa (DARDENGO et al., 2013), sendo indicado um valor mínimo de 0,20 para esta cultura (HUNT, 1990).

As mudas de café são normalmente transplantadas de 5 a 6 meses após a germinação das sementes, com 5 a 7 pares de folhas (BALIZA et al. 2013), sendo relevante a utilização de substratos que atendam a demanda de nutrientes pela planta. A escolha do substrato é fundamental, pois ele afeta a estrutura do solo, a capacidade de retenção e translocação da água e de nutrientes, além de aumentar a capacidade de troca de cátions, auxiliar no arejamento e fornecer de forma lenta e gradual os nutrientes às plantas (FERNANDES et al., 2013a; DELARMELINA et al., 2013). Estas características irão influenciar de forma direta ou indireta na fertilidade do local de plantio.

O substrato empregado na produção de mudas de café é responsável por $38 \%$ do custo de produção (VALLONE et al., 2010), portanto uma possível utilização de materiais orgânicos provenientes de animais criados sob confinamento, tais como os bovinos, suínos, aves e coelhos, tende a diminuir esse custo, favorecendo economicamente os viveiricultores.

Alguns trabalhos já foram conduzidos com diferentes fontes de matéria orgânica na produção de plantas de café em tubetes. Materiais orgânicos como a vermiculita, cama aviária, esterco bovino e húmus de minhoca proporcionam benefícios na sua produção, dependendo da dose no substrato (ANDRADE NETO et al., 1999; DIAS et al., 2009; ALMEIDA et al., 2011).

A busca por novas fontes de matéria orgânica na produção de mudas de café é importante, pois os sistemas produtivos são dinâmicos. A escolha da matéria orgânica para a composição de substratos deve ser feita conforme a disponibilidade, as características físicas e químicas, peso e, sobretudo, custo. Assim, este estudo foi realizado com o objetivo de avaliar aspectos agronômicos de mudas do cafeeiro (C. arabica L.), cultivar Topázio MG1190, produzidas em tubetes com a utilização de diferentes proporções de materiais orgânicos no substrato comercial

\section{Material e Métodos}

O experimento foi conduzido entre outubro de 2013 e abril de 2014 no Instituto Federal de Ciência e Tecnologia do Triângulo Mineiro - Campus Uberlândia, Minas Gerais. A temperatura média anual é de $22^{\circ} \mathrm{C}$ e altitude média de $622 \mathrm{~m}$. O clima se define como tropical Aw, com duas estações bem contrastantes; seca com temperaturas amenas e outra chuvosa com elevadas temperaturas, umidade relativa do ar média anual de 71,2\% (ALVARES et al., 2013).

Para formação das mudas foram utilizadas sementes do cultivar Topázio MG 1190, repicadas no estádio "orelha de onça" para tubetes com volume de $180 \mathrm{~mL}$ conforme metodologia descrita por Dias e Melo (2009). As mudas foram repicadas no dia 01 de outubro de 2013, as primeiras avaliações iniciaram no dia 20 de março de 2014.

O experimento foi conduzido em viveiro coberto com tela sombrite, de cor preta, com passagem de $50 \%$ de luz, sendo posicionada a dois metros acima dos tubetes e na parte lateral do viveiro. Para manter a umidade dos substratos foi utilizado o sistema de irrigação de micro aspersão por nebulização, com vazão de $1201 \mathrm{~h}^{-1}$, com turno de rega de seis em seis horas, com duração de cinco minutos por vez.

Os tratos culturais recomendados por Matiello et al. (2010) para produção de mudas foram seguidos da semeadura até a avaliação do experimento, que foi destrutiva ao final do período do experimento.

Adotou-se o delineamento experimental em blocos casualizados (DBC), com quatro repetições, em esquema fatorial $4 \times 4$. Foram utilizadas quatro fontes de matéria orgânica (esterco de coelho, esterco bovino, 
cama de frango e esterco suíno) em quatro proporções destes materiais no substrato comercial Bioplant ${ }^{\circledR}(0 \%$, $20 \%, 40 \%$ e $60 \%$ ). Cada parcela foi constituída por 7 plantas. Foi utilizado o substrato comercial Bioplant Prata $\mathrm{HT}^{\circledR}$ suplementado com $1 \mathrm{~g}$ do Osmocote ${ }^{\circledR}$ cuja composição é 15-09-12 (N-P $\left.\mathrm{O}_{5}-\mathrm{K}_{2} \mathrm{O}\right)$ acrescentado os micronutrientes $(\mathrm{Mg}=1 \%, \mathrm{~S}=3 \%, \mathrm{~B}=0,02 \%, \mathrm{Cu}=$ $0,05 \%, \mathrm{Fe}=1 \%, \mathrm{Mn}=0,1 \%, \mathrm{Mo}=0,01 \%, \mathrm{Zn}=0,05 \%)$ por recipiente.

A avaliação do crescimento e da qualidade da muda ocorreu aos 171 dias após o transplante. Foram determinadas as seguintes características: a) altura da parte aérea $(\mathrm{AP})$, expresso em $\mathrm{cm}$, medida com régua milimetrada, a partir do coleto até a gema apical; b) número de pares de folhas (NPF); c) área foliar (AF), expresso em $\mathrm{cm}^{2}$, medida com régua milimetrada, resultado da multiplicação da largura pelo comprimento, cujo resultado foi corrigido pelo fator de multiplicação 0,667 (valor padrão para folhas de café); d) diâmetro de coleto (DC), expresso em $\mathrm{mm}$, medido por meio de paquímetro digital (Stainless ${ }^{\circledR} 150 \mathrm{~mm}$ ), com grau de acurácia de 0,01 $\mathrm{mm}$; e) massa seca da parte aérea (MSPA) e da raiz (MSRA), expressa em gramas, determinada em balança digital após secagem em estufa de circulação forçada a $75{ }^{\circ} \mathrm{C}$ até peso constante; f) relação da altura da parte aérea com o diâmetro do coleto $(\mathrm{RAD}=\mathrm{AP} / \mathrm{DC})$; g) relação da matéria seca da parte aérea com a matéria seca de raízes (RPAR = MSPA/MSR); e h) índice de qualidade de Dickson obtido pela fórmula: IQD = [matéria seca total/(RAD + RPAR)] (DICKSON et al., 1960).

Os dados foram submetidos aos testes de normalidade dos erros e de homocedasticidade de variâncias, respectivamente por meio dos testes de Shapiro-Wilks e Bartlett e à análise de variância empregando o software Sisvar $^{\circledR} \quad$ (FERREIRA, 2008) e se encontrada significância pelo teste de $\mathrm{F}$ ao nível de $5 \%$ de probabilidade à análise de regressão. Os pontos de máximo foram determinados por meio da derivada primeira das equações de regressão de segundo grau. Os gráficos foram gerados utilizando-se o programa computacional Excel for Windows ${ }^{\circledR}$.

\section{Resultados e Discussão}

Os dados atenderam às pressuposições de normalidade dos erros e de homocedasticidade de variâncias de acordo com os testes aplicados e portanto não foi necessário transformação de dados. Pela análise de variância das características de desenvolvimento de mudas de café Topázio MG 1190 foi possível observar efeito significativo entre interação entre matéria orgânica e doses para AP, NPF, AF, DC, MSPA, MSRA, RAD, RPAR e IQD (Tabela 1). Para essas características optou-se por realizar o desdobramento das doses dentro de cada tipo de matéria orgânica.

Para AP, foi verificado comportamento quadrático, com o máximo crescimento na dose estimada de $75 \%$ de esterco de coelho no substrato e nesta dose as mudas cresceriam até a altura de $21,7 \mathrm{~cm}$. Para as demais fontes de material orgânico calculou-se o máximo crescimento na dose de $16,5 \%, 13 \%$ e $13,6 \%$ para cama de frango, esterco suíno e esterco bovino no substrato, respectivamente (Figura 1).

Tabela 1. Resumo da análise de variância com os respectivos valores de F das características avaliadas: AP (altura de planta), NPF (número de pares de folhas), AF (área foliar), DC (diâmetro do caule), MSPA (matéria seca da parte aérea), MSRA (matéria seca da raiz), RAD (relação altura e diâmetro do caule), RPAR (relação parte aérea e raiz e IQD (Índice de qualidade de Dickson). Uberlândia, MG, 2017.

\begin{tabular}{|c|c|c|c|c|c|c|c|c|c|c|c|}
\hline \multirow[b]{2}{*}{ Fontes de Variação } & \multirow[b]{2}{*}{ GL } & \multicolumn{10}{|c|}{ Valores de F } \\
\hline & & $\mathrm{AP}(\mathrm{cm})$ & & NPF & & $\mathrm{AF}(\mathrm{cm}$ & & $\mathrm{DC}(\mathrm{mm})$ & & MSPA (gr & \\
\hline Tipos de Esterco & 3 & 40,206 & $* *$ & 14,56 & $* *$ & 29,463 & $* *$ & 46,375 & $* *$ & 38,311 & $* *$ \\
\hline Doses & 3 & 58,029 & $* *$ & 22,96 & $* *$ & 18,612 & $* *$ & 77,74 & $* *$ & 18,082 & $* *$ \\
\hline Esterco x Doses & 9 & 17,43 & $* *$ & 4,777 & $* *$ & 7,901 & $* *$ & 11,895 & $* *$ & 10,261 & $* *$ \\
\hline Blocos & 3 & 2,971 & $*$ & 2,726 & NS & 5,076 & $* *$ & 3,842 & $*$ & 8,894 & $* *$ \\
\hline Total & 63 & & & & & & & & & & \\
\hline \multirow[t]{2}{*}{$\mathrm{CV} \%$} & & 15,82 & & 26,05 & & 25,27 & & 14,74 & & 25,76 & \\
\hline & & MSRA (gr) & & & & & RPAR & & & IQD & \\
\hline Tipos de Esterco & 3 & 27,656 & $* *$ & & 59 & $* *$ & 25,409 & $* *$ & & 21,625 & $* *$ \\
\hline Doses & 3 & 27,652 & $* *$ & & 67 & $* *$ & 22,428 & $* *$ & & 13,444 & $* *$ \\
\hline Esterco x Doses & 9 & 9,931 & $* *$ & & 63 & $* *$ & 13,8 & $* *$ & & 6,959 & $* *$ \\
\hline Blocos & 3 & 0,431 & NS & & & NS & 14,178 & $* *$ & & 0,564 & $*$ \\
\hline Total & 63 & & & & & & & & & & \\
\hline $\mathrm{CV} \%$ & & 21,67 & & & ,25 & & 22 & & & 27,42 & \\
\hline
\end{tabular}

NS não significativo. *significativo a $5 \%$ de probabilidade e $* *$ significativo a $1 \%$ de probabilidade pelo teste de $\mathrm{F}$. 
A altura, avaliada isoladamente, tem sido utilizada erroneamente como uma boa característica para expressar a qualidade de mudas. Mudas de café muito altas, com característica de estiolamento, podem ser advindas de um ajuste fisiológico em busca de luz a fim de evitar a baixa irradiância do ambiente (DARDENGO et al., 2013).

A aplicação da maior dose de esterco bovino e suíno inibiu o crescimento das plantas, resultando na morte das plantas de café. O efeito adverso da adição de matéria orgânica no substrato para produção de mudas de café arábica já havia sido detectada para altas doses de esterco bovino e resíduo de fumo (DIAS; MELO, 2009). Dias et al. (2009) recomendam não exceder em $30 \%$ a dose de esterco bovino no substrato comercial Plantmax ${ }^{\circledR}$ para produção de mudas de café arábica produzidas em tubetes pois, o desenvolvimento e crescimento de mudas de café podem ser paralisados. Valores elevados de nitrogênio, como os relatados para o esterco de galinha, esterco suíno e por último, bovino, podem ser considerados responsáveis pela causa da morte de plantas em doses próximas a $60 \%$, conforme pode ser constatado nesse experimento (KONZEN, ALVARENGA, 2005; RAIJ et al., 1997).

Quanto ao NPF, observou-se que o esterco de coelho resultou em melhores resultados comparando-se aos demais tratamentos em todas as doses testadas, com crescimento máximo na dose de $33 \%$ adicionado ao substrato. Adversamente, a cama de frango levou a uma redução no NPF a partir da dose máxima calculada em $6,9 \%$, ou seja, inferior à primeira dose testada nesse experimento. Os estercos bovino e suíno incrementaram o NPF até a dose máxima calculada de $17 \%$ e 12,4\% respectivamente (Figura 2).

Deve-se atentar que na dose de $60 \%$, os estercos suíno e bovino levaram a uma fitotoxidez representada pela desfolha das plantas seguida por morte. Desse modo, as demais variáveis agronômicas avaliadas nesse trabalho não foram coletadas para a dose de $60 \%$ nos tratamentos aqui destacados já que houve a morte das mudas. O esterco de coelho, independente da dose aplicada, resultou em maior AF comparada aos demais tratamentos utilizados nesse experimento. Calculou-se a dose máxima para essa característica encontrando-se os valores de $16,90 \%, 17,95 \%, 32,15 \%$ e $39,2 \%$ para o esterco suíno, esterco bovino, cama de frango e esterco de coelho respectivamente, adicionado ao substrato comercial testado (Figura 3).

A avaliação de mudas considerando a área foliar é uma característica relevante, pois é a partir das folhas que a planta faz a captação da energia solar, fixa $\mathrm{CO}_{2}$ e os utiliza para a produção de elementos essenciais que irão agir na melhora do seu processo na fotossíntese e consequentemente em maior crescimento da muda (MARUR; FARIA; 2006; DARDENGO et al., 2013). Porém deve-se destacar que o crescimento da AF também é determinado pelo sombreamento, como compensação a uma menor interceptação de luminosidade (DARDENGO et al., 2013).

O DC é uma característica considerada menos afetada por fatores externos; ambientais como sombreamento e tipo de recipiente de produção (DARDENGO et al, 2013). Constatou-se aumento do DC conforme acréscimo de cama de frango, esterco bovino e esterco suíno até a dose de $27,8 \%, 12,4 \%$ e $11 \%$, respectivamente, no substrato comercial. Assim, como para as demais características, o esterco de coelho foi superior aos demais tratamentos testados (Figura 4).

Ao contrário dos demais tratamentos, a cama de frango reduziu o DC com acréscimo da dose ao substrato artificial, caracterizando-se como sintoma de fitotoxicidade. Esses resultados são contrários aos observados por Marana et al. (2008) que recomendam a utilização de substrato à base de matéria orgânica em detrimento de substrato artificial quando não é realizada suplementação com fertilizante.

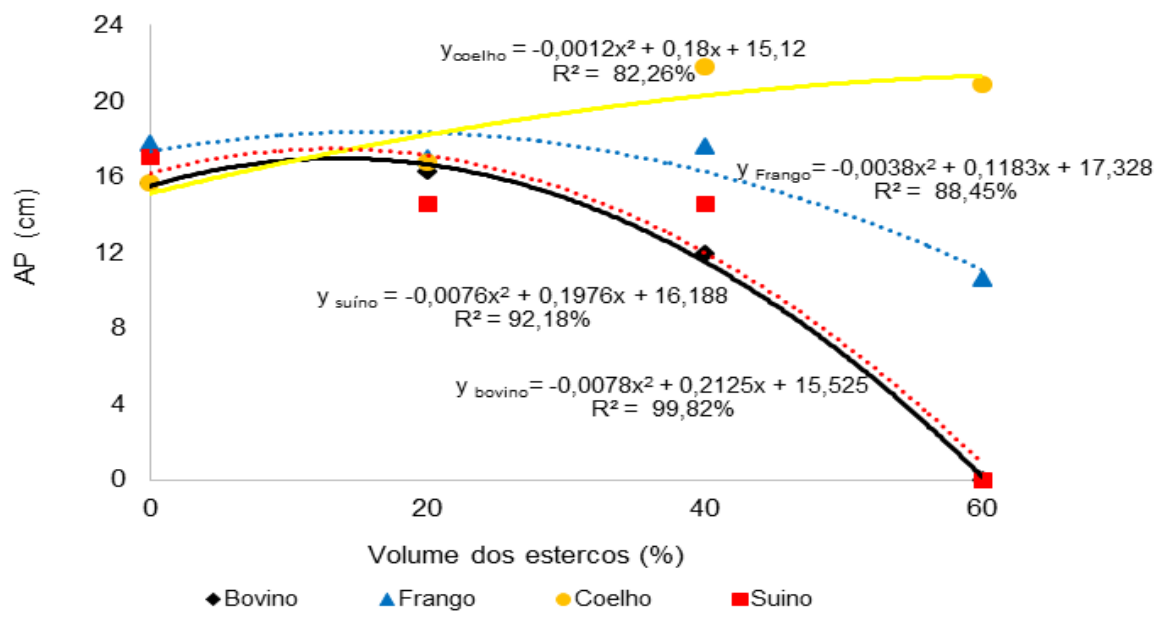

Figura 1. Altura de plantas (AP) de café cv. Topázio MG 1190 obtidas em função de diferentes composições de substratos. Uberlândia, MG, 2014. 


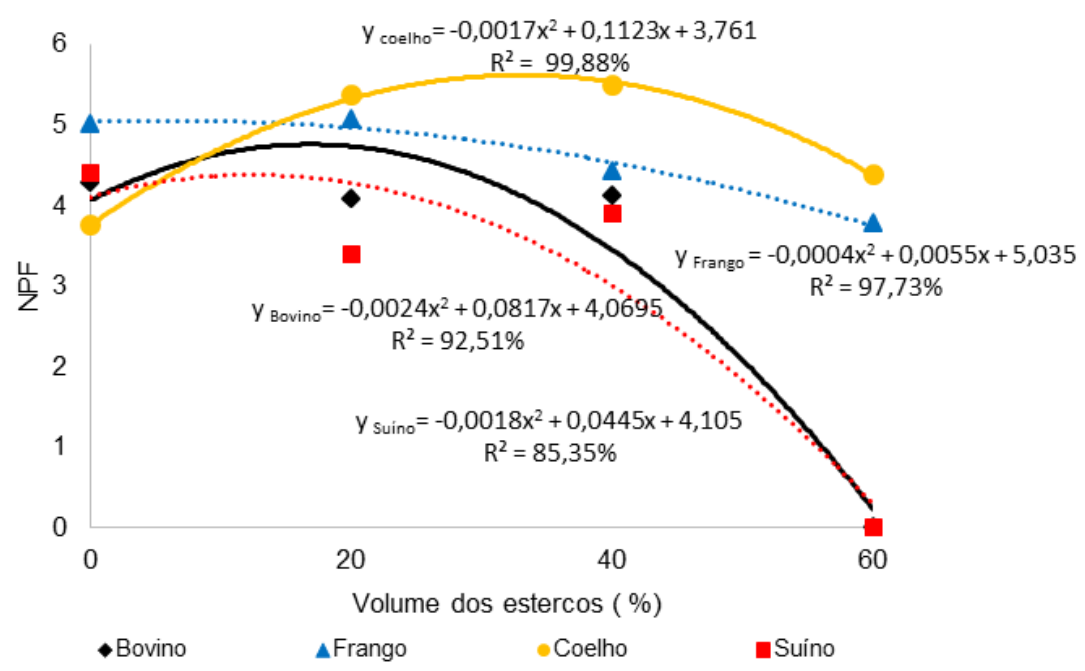

Figura 2. Número de pares de folhas de plantas (NPF) de café cv. Topázio MG 1190 obtidas em função de diferentes composições de substratos. Uberlândia, MG, 2014.

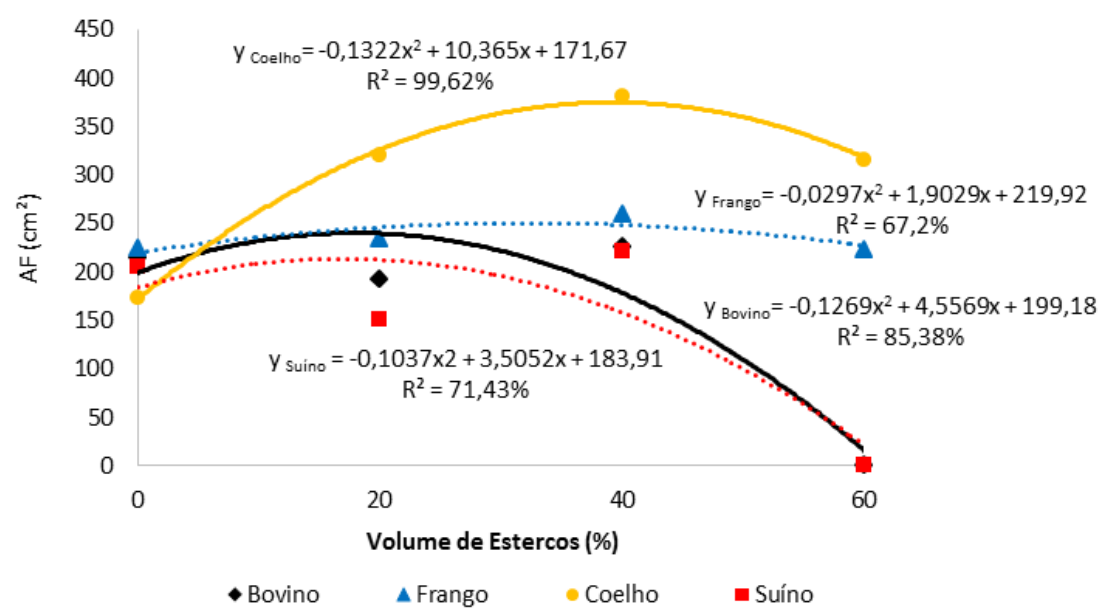

Figura 3. Área foliar (AF) de plantas de cafeeiro obtidas em plantas de cafeeiro submetidas a diferentes composições de substratos Uberlândia, MG, 2014.

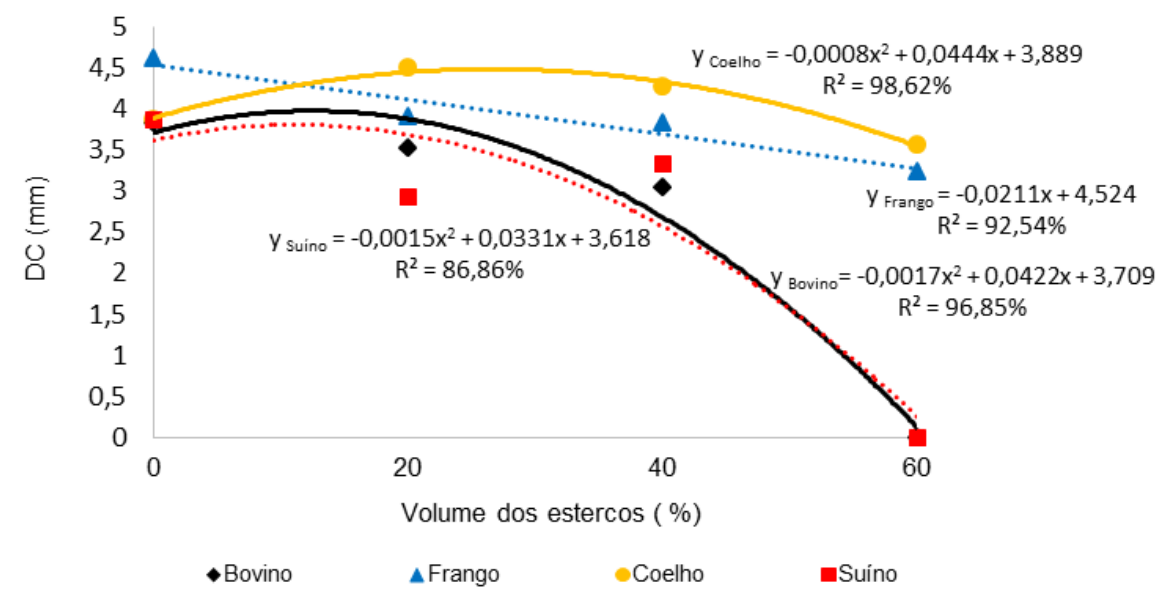

Figura 4. Diâmetro de caule (DC) obtidas em plantas de cafeeiro submetidas a diferentes composições de substratos Uberlândia, MG, 2014. 
Quanto à MSPA e MSRA, foi constatado que o esterco de coelho resultou em maiores valores para essas caraterísticas, com valor máximo de MSPA e MSRA calculado na dose de $52,8 \%$ e $40,3 \%$ respectivamente (Figura 5a, 5b).

A cama de frango elevou a MSPA de forma linear até a última dose testada e, adversamente, reduziu a MSRA também de forma linear, apresentando-se desta forma como o segundo melhor tratamento para ambas as características avaliadas.

Os demais tratamentos alcançaram, em média, valores inferiores para tais características comparadas ao esterco de coelho e cama de frango. $\mathrm{O}$ valor máximo de MSPA e MSRA para o tratamento com esterco bovino foi calculado em $22,8 \%$ e $12,4 \%$ respectivamente. Para o esterco de suíno o valor máximo de MSPA e MSRA foi calculado em 16,1\% e $11,1 \%$ respectivamente.

Para Dias e Melo (2009) em trabalho com café arábica produzido em tubetes de $120 \mathrm{~mL}$, observaram redução da MSPA e MSRA das mudas à medida que aumentaram a proporção de esterco bovino, enquanto que a adição de cama de peru até a proporção de $53,12 \%$ no substrato, elevaram essas características. A MSRA bem como demais aspectos do sistema radicular são importantes na caracterização de mudas de café, pois raízes profundas, bem distribuídas e ramificadas normalmente levam a um bom desenvolvimento da planta visto que são responsáveis pela extração de água, íons do substrato e pela ancoragem da planta no solo (TOMAZ et al., 2009).

Raízes pequenas, pouco vigorosas e pouco ramificadas resultam em plantas menores, atrasando seu desenvolvimento fenológico e consequente resposta produtiva da lavoura cafeeira. Quanto mais vigorosa estiver a muda ao ser plantada melhor será a resposta produtiva nos anos subsequentes. Plantas raquíticas, ou não aclimatadas levam à extensão da juvenilidade das mesmas e consequente atraso ao início de produção (BALIZA et al., 2013).

$\mathbf{A}$

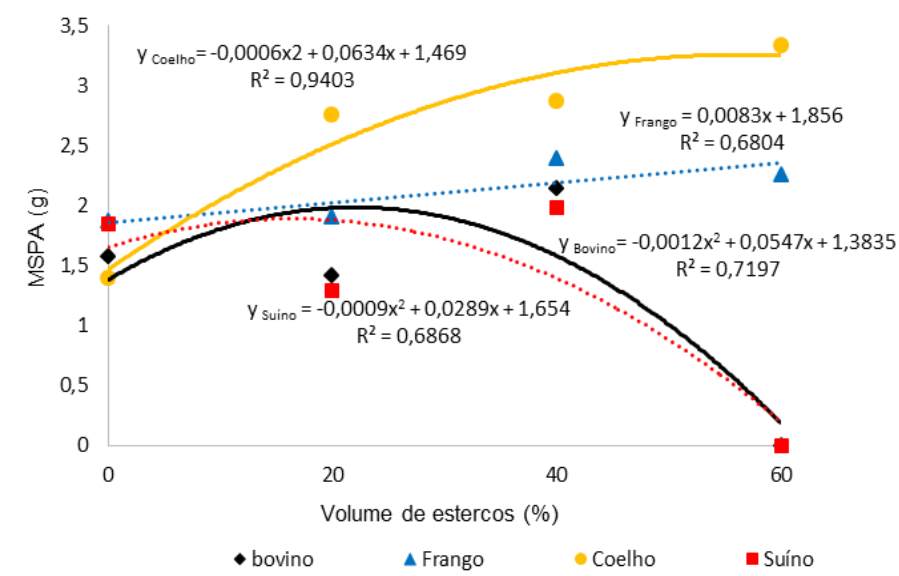

B

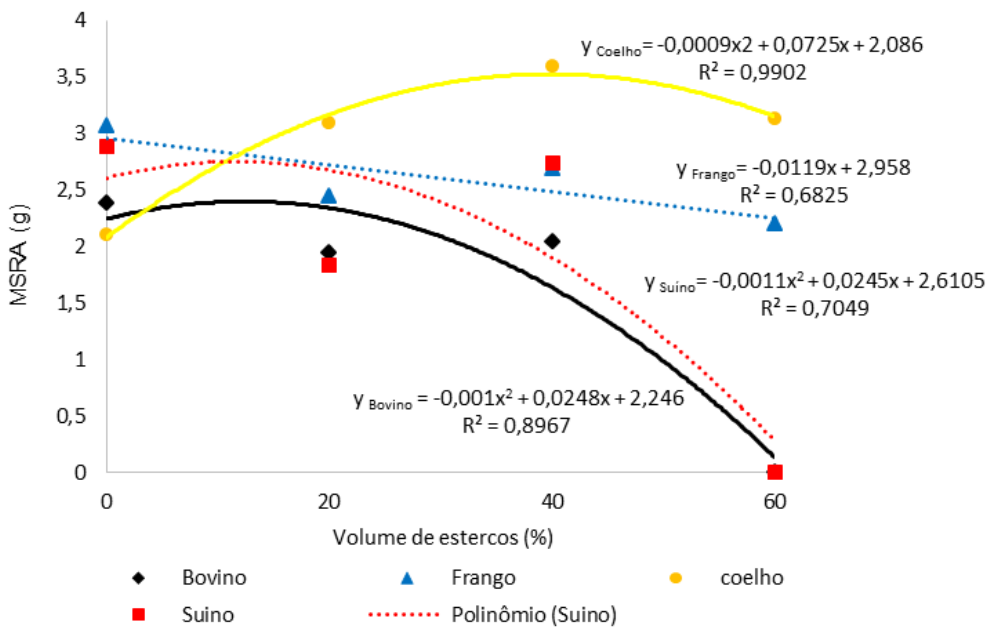

Figura 5. Massa seca da parte aérea (MSPA) (A), da raiz (MSRA) (B), obtidas em plantas de cafeeiro submetidas a diferentes composições de substratos. Uberlândia, MG, 2014. 
Quaisquer ganhos na MSPA e MSRA representam melhoria na produção de mudas de café (COGO et al., 2011) e, portanto, devem ser recomendadas ao produtor de mudas com o objetivo de se reduzir a juvenilidade das mesmas (BALIZA et al., 2013).

Apesar das avaliações quantitativas serem amplamente utilizadas e boas indicadoras do crescimento de mudas de café, podem induzir a erros quando utilizadas isoladamente. Distorções provenientes do excesso de nitrogênio, por exemplo, ou do crescimento foliar em detrimento do sistema radicular provocam a utilização de índices de crescimento, que são relações entre os parâmetros de crescimento. Nesse trabalho foram calculados o RAD (relação da altura da parte aérea com o diâmetro do coleto), RPAR (relação da matéria seca da parte aérea com a matéria seca de raízes) e IQD (Índice de Dickson).

O maior valor de RAD, com 6,9, foi encontrado para esterco de coelho na dose de 60\% (Figura 6). O esterco de suíno, de bovino e cama de frango apresentaram RAD máximo de 5,43, 5,07 e 4,64 nas doses de 18,1\%, $18,9 \%$ e $29 \%$ respectivamente. Estes valores estão acima do valor recomendado para a cultura que é de 4,0 conforme Marana et al. (2008).

Ao se calcular o RPAR, o melhor tratamento testado foi o esterco de coelho na dose calculada de $48,1 \%$ resultando no maior valor que foi de 1,1 (Figura 7). O esterco de suíno, de bovino e cama de frango apresentaram RPAR máximo de 0,80, 0,98 e 2,11 nas doses estimadas de $21,7 \%, \quad 24 \%$ e $100 \%$ respectivamente. Destaca-se o estiolamento estimado na máxima dose de cama de frango, calculada em $100 \%$ da dose. A cama de frango é rica em nitrogênio que leva a um estiolamento da planta em detrimento do crescimento radicular. De outro lado, o esterco de suíno resultou em menor RPAR.

Esses valores de RPAR são semelhantes aos obtidos por Dardengo et al. (2013) cujo valor médio foi de 1,2 para Coffea canephora Pierre var. Robusta, produzido em tubetes e sacolas sob diferentes níveis de sombreamento e inferiores aos encontrados por Marana et al. (2008) cujo valor médio para essa característica variou de 4 a 7, para Coffea arabica L. cv. Catuaí Vermelho IAC 99 também em tubetes.

Pelo cálculo do IQD foi possível constatar a superioridade do esterco de coelho com máximo IQD de 1,31 na dose calculada em $32,9 \%$, seguido pelos demais tratamentos que resultaram em valores de IQD muito semelhantes (Figura 8). Isso se deve provavelmente às características dessa matéria orgânica que segundo Queiroz et al. (2014), pode ser classificado como um fertilizante orgânico simples com potencial para mineralização em curto prazo, em função das relações $\mathrm{C} / \mathrm{P}$ e $\mathrm{C} / \mathrm{S}$ abaixo dos valores estabelecidos como indicadores $(\mathrm{C} / \mathrm{P} \leq 200$ e $\mathrm{C} / \mathrm{S} \leq 300)$, além de relação $\mathrm{C} / \mathrm{N}$ próxima do valor indicado como referência $(\mathrm{C} / \mathrm{N} \leq$ 20).

Machado e Ferreira (2011) indicaram que o esterco de coelho apresenta composição média de 1,5 a 2,5\% de N, 1,4 a $1,8 \%$ de $\mathrm{P}$ e 0,5 a $0,8 \%$ de K. A composição média de $\mathrm{N}$ no esterco de coelho assemelha-se aos teores encontrados em estercos de bovino (2,03\%; $2,27 \%$ ), sendo um pouco inferior aos estercos de suíno $(2,96 \% ; 3,18 \%)$ e galinha $(4,03 \% ; 3,0 \%)$ (KONZEN;ALVARENGA, 2005; RAIJ et al., 1997).

O esterco de coelho apresenta teores de $\mathrm{P}$ que podem ser menores ou maiores que o presente em estercos de outras fontes, tal como citado por Raij et al. (1997) e Konzen e Alvarenga (2005) para esterco de galinhas $(1,78 \%$ e $2,4 \%)$, bovinos $(1,8 \%$ e $1,59 \%)$ e suínos $(0,9 \%$ e $4,0 \%)$.

O máximo IQD para a cama de frango, esterco bovino e esterco de suíno foram de 0,9, 0,88 e 0,87 calculados para as doses de $25 \%, 17,4 \%$ e $5,2 \%$ respectivamente dos tratamentos no substrato. Importante destacar que todos os tipos de matéria orgânica resultaram em mudas consideradas de boa qualidade pois resultaram em IQD superiores a 0,20 , sendo esse o valor mínimo recomendado para mudas de café (MARANA et al., 2008).

A adição de diferentes fontes de material orgânico realizadas nesse trabalho permitiu constatar o efeito benéfico dos mesmos em relação às testemunhas sem nenhuma mistura ao substrato comercial utilizado para alguns caracteres avaliados até uma dose máxima. Pelo cálculo de IQD, é possível recomendar uma dose máxima para cada um dos tipos de matéria orgânica adicionadas aos substratos utilizados nesse experimento. Segundo Dardengo et al. (2013), os valores de MSPA e MSRA apresentam altas correlações positivas com IQD.

Credita-se à matéria orgânica a responsabilidade por alterações químicas ao substrato como aumento da capacidade de troca de cátions (CTC) com todos os seus benefícios e por alterações físicas ao mesmo, representado pelo aumento da porosidade total e retenção de água (FERNANDES et al., 2013a). A diferença entre os tratamentos para o IQD, índice que integra as demais características agronômicas avaliadas nesse experimento, pode ser explicada por vários fatores, dentre eles está a diferença nas reações de decomposição de cada tipo de esterco. Segundo Fernandes et al. (2013b), a estrutura do solo é beneficiada quando a decomposição dos restos vegetais for maior e a formação de substâncias intermediárias da decomposição for mais ativa. Essa velocidade de decomposição e a estrutura do substrato interferem diretamente na disponibilização, por determinado tempo, dos nutrientes para as mudas. 


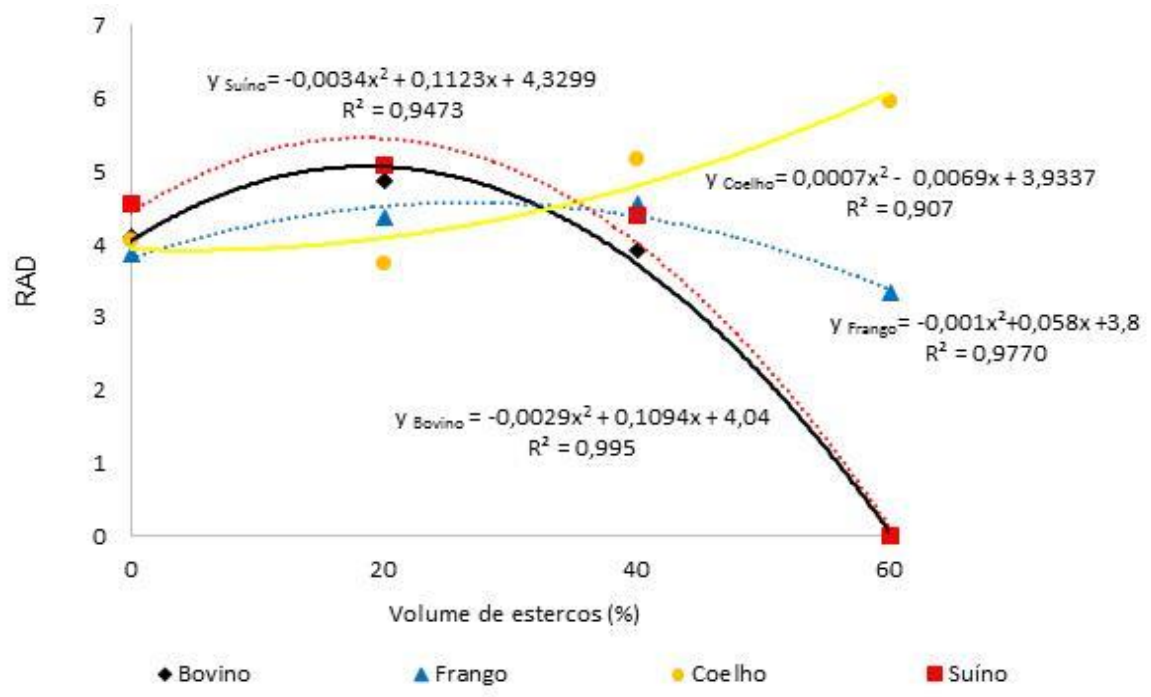

Figura 6. Relação da altura da parte aérea com o diâmetro do coleto (RAD), obtidas em plantas de cafeeiro cv. Topázio MG 1190 submetidas à diferentes composições de substratos. Uberlândia, MG, 2014.

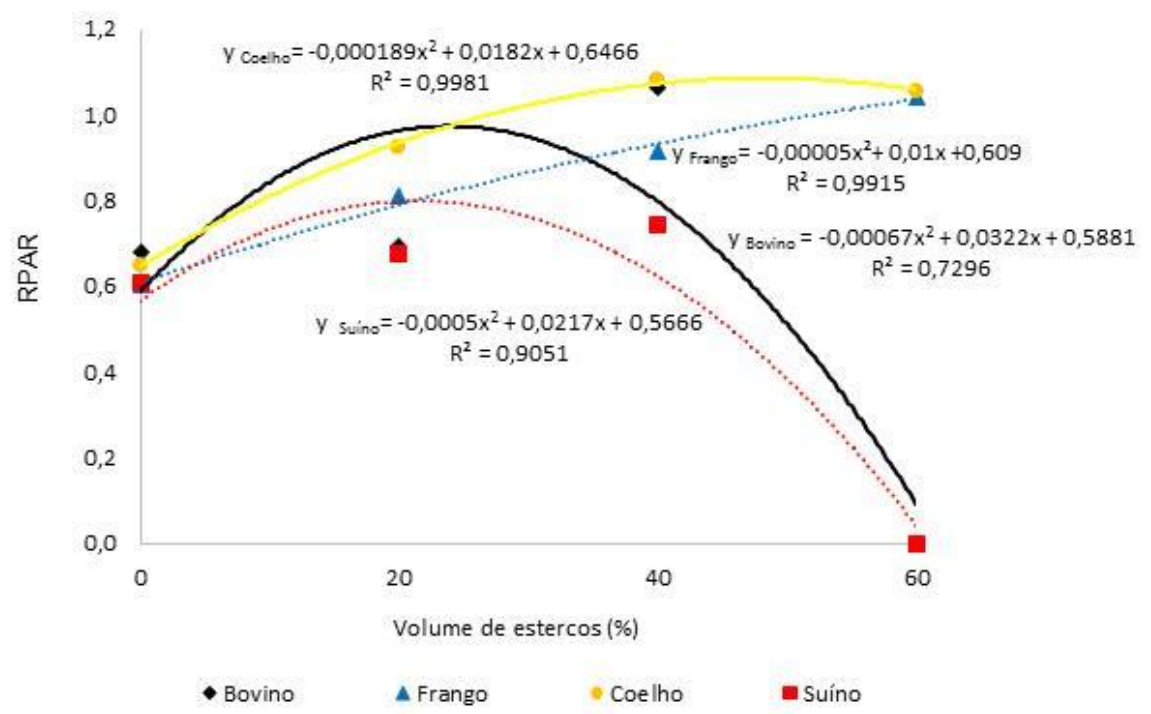

Figura 7. Relação da matéria seca da parte aérea com a matéria seca de raízes (RPAR), obtidas em plantas de cafeeiro cv. Topázio MG 1190 submetidas a diferentes composições de substratos. Uberlândia, MG, 2014.

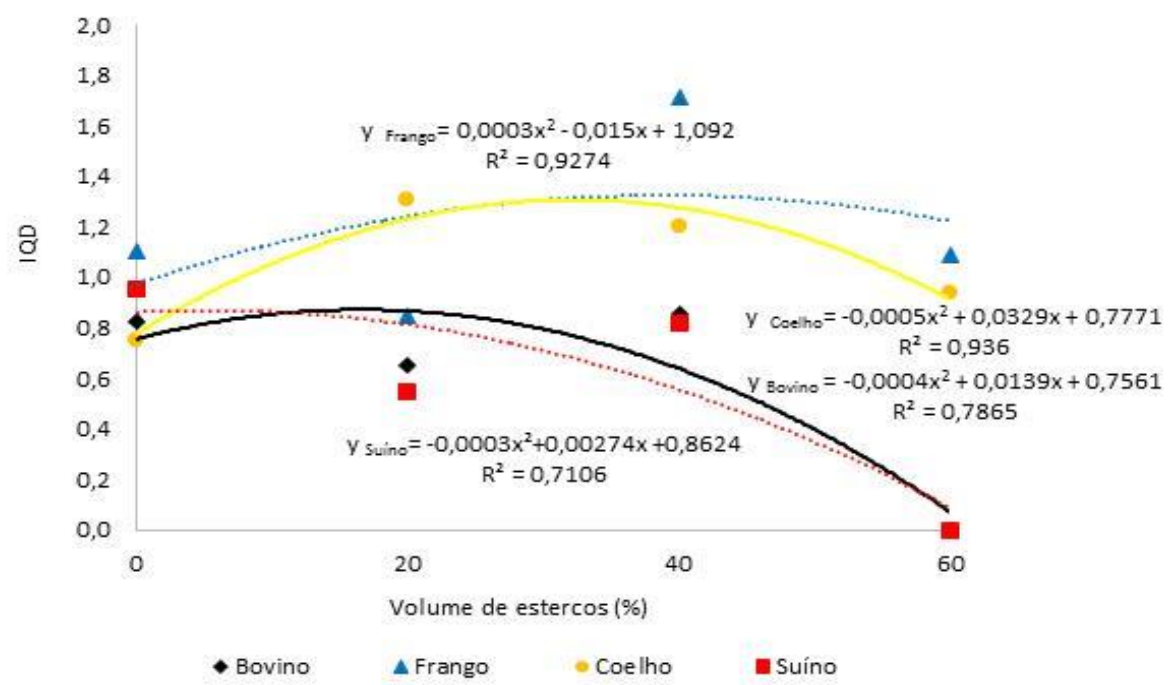

Figura 8. Índice de Dickson (IQD), obtidas em plantas de cafeeiro cv. Topázio MG 1190 submetidas a diferentes composições de substratos. Uberlândia, MG, 2014. 


\section{Conclusões}

Para mudas de café arábica cv. Topázio MG 1190, produzidos em tubetes de $120 \mathrm{~mL}$, recomenda-se o uso do esterco de coelho até a dose de $32,9 \%$ adicionado ao substrato Bioplant Prata $\mathrm{HT}^{\circledR}$ pois proporciona o maior valor de IQD, calculado em 1,31.

A cama de frango adicionada ao substrato Bioplant Prata $\mathrm{HT}^{\circledR}$ favorece o desenvolvimento das mudas do cafeeiro cultivar Topázio até a dose de $25 \%$ no substrato proporcionando um IQD de 0,9.

O esterco suíno e bovino não deve ser recomendado em doses superiores a $5,2 \%$ e $17,4 \%$, adicionados ao substrato Bioplant Prata $\mathrm{HT}^{\circledR}$, pois reduzem o desenvolvimento das mudas, representado pelo rápido decréscimo a partir do IQD máximo de 0,88 e 0,87 respectivamente.

\section{Referências Bibliográficas}

ALMEIDA, S. L. S.; COGO, F.D.; GONÇALVES, B. O.; RIBEIRO, B. T.; CAMPOS, K. A.; MORAIS, A. R. Adição de resíduos orgânicos ao substrato para produção de mudas de café em tubete. Revista Agroambiental, Pouso Alegre-MG, v. 3, n. 2, p. 9-13, 2011.

ALVARES, C. A.; STAPE, J. L.; SENTELHAS, P. C.; GONÇALVES, J. L. M.; SPAROVEK, G. Köppen's climate classification map for Brazil. Meteorologische Zeitschrift, Stuttgart-BW, v.22, n 6, p 711- 728, 2013.

BALIZA, D. P.; OLIVEIRA, A. L.; DIAS, R. A. A.; GUIMARÃES, R. J.; BARBOSA, C. R. Antecipação da produção e desenvolvimento da lavoura cafeeira implantada com diferentes tipos de mudas. Coffee Science, Lavras-MG, v. $8, \quad$ n. 1, p. 61-68, 2013. Disponível em: < http://www.coffeescience.ufla.br/index.php/Coffeescience/arti cle/view/348/pdf>. Acesso em: 12 ago. 2016.

COGO, F. D.; ALMEIDA, S. L. S.; VIEIRA, R. J.; LOPES, F. A. B.; CAMPOS, K. A.; RAMALHO, A. Crescimento de mudas de diferentes cultivares de cafeeiro em função da fertilização orgânica do substrato. Enciclopédia Biosfera, Goiânia-GO, v. 7, n. 12; p. 1-9. 2011. Disponível em: < http://www.conhecer.org.br/enciclop/2011a/agrarias/Crescime nto\%20de\%20mudas.pdf $>$. Acesso em 15 set. 2016.

COGO, F. D.; SILVA, E. A.; CAMPOS, K. A. Formação de mudas de cafeeiro sob doses crescentes de fósforo. Enciclopédia Biosfera, Goiânia-GO, v. 8, n. 14; p. 598-605. 2012. Disponível em: < http://www.conhecer.org.br/enciclop/2012a/ agrarias/formacao.pdf>. Acesso em 15 set. 2016.

CONAB. COMPANHIA NACIONAL DE ABASTECIMENTO. $1^{\circ}$ Levantamento CONAB da safra de café. 2017. Disponível em: < http://www.conab.gov.br/OlalaCMS/uploads/arquivos/17_01_ 17_14_51_54_boletim_cafe_-_janeiro_de_2017.pdf >. Acesso em: 25 mar. 2017.

DARDENGO, M. C. J. D.; SOUSA, E. F.; REIS, E. F.; GRAVINA, G. A. Crescimento e qualidade de mudas de café conilon produzidas em diferentes recipientes e níveis de sombreamento. Coffee Science, Lavras-MG, v. 8, n. 4, p. 500509, 2013. Disponível em: < http://coffeescience.ufla.br/index.php/Coffeescience/article/vie w/512/pdf_68>. Acesso em 10 abril. 2017.

DELARMELINA, W. M.; CALDEIRA, M. V. W.; FARIA, J. C. T.; GONÇALVES, E. O. Uso de lodo de esgoto e resíduos orgânicos no crescimento de mudas de Sesbania virgata (Cav.) Pers. Revista Agroambiente On-line, Boa Vista-RR, v. 7, n. 2, p. 184-192, 2013.

DIAS, R.; MELO, B. D.; RUFINO, M. A.; SILVEIRA, D, L.; MORAIS, T. P.; SANTANA, D. G. Fontes e proporções de material orgânico para a produção de mudas de cafeeiro em tubetes. Ciência e Agrotecnologia, Lavras-MG, v. 33, n. 3, p. 758-764, 2009.

DIAS, R.; MELO, B. Proporção de material orgânico no substrato artificial para a produção de mudas de cafeeiro em tubetes. Ciência e Agrotecnologia, Lavras-MG, v. 33, n. 1, p. 144-152, 2009.

DICKSON, A.; LEAF, A. L.; HOSNER, J. F. Quality appraisal of white spruce and white pine seedling stock in nurseries. Forestry Chronicle, Mattawa-ON, Canadá v. 36, n.1; p. 10-13, 1960. Disponível em: $<$ http://pubs.cififc.org/doi/pdf/10.5558/tfc36010-1>. Acesso em: 10 abril. 2017.

FERNANDES, A. L. T.; SANTINATO, F.; FERREIRA, R. T.; SANTINATO, R. Adubação orgânica do cafeeiro, com uso do esterco de galinha, em substituição à adubação mineral. Coffee Science, Lavras-MG, v. 8, n. 4, p. 486-499, 2013 a. Disponível em:

http://www.coffeescience.ufla.br/index.php/Coffeescience/arti cle/view/505/pdf_67>. Acesso em 11 set. 2016.

FERNANDES, A. L. T.; SANTINATO, F.; FERREIRA, R. T.; SANTINATO, R. Redução da adubação mineral do cafeeiro arábica. Coffee Science, Lavras-MG, v. 8, n. 3, p. 324-336, 2013b. Disponível em: < http://www.coffeescience.ufla.br/index.php/ Coffeescience/article/viewFile/454/pdf_44>. Acesso em 11 set. 2016.

FERREIRA, D. F. SISVAR - Sistema de Análise de Variância. Versão 5. 3. Lavras-MG: UFLA, 2010.

HUNT, G. A. Effect of styroblock design and cooper treatment on morphology of conifer seedlings. In: Rose, R.; Campbell, S.J.; Landis, T. D. Target seedling symposium: Proceedings, combined meeting of the Western Forest Nursery Associations. Fort Collins-CO: Department of Agriculture, Forest Service, Rocky Mountain Forest and Range Experiment Station, 1990. 286 p.

KONZEN, E.A.; ALVARENGA, R.C. Manejo e utilização de dejetos animais: aspectos agronômicos e ambientais. Sete Lagoas-MG: EMBRAPA MILHO E SORGO, 2005, 16p. (Embrapa Milho e Sorgo, Circular técnica 63.) Disponível em: < https://goo.gl/0nhR7e>. Acesso em 12 abril 2017.

MARANA, J. P.; MIGLIORANZA, E.; FONSECA, É. P.; KAINUMA, R. H. Índices de qualidade e crescimento de mudas de café produzidas em tubetes. Ciência Rural, Santa Maria-RS, v. 38, n. 1, p. 39-45, 2008 
MARUR, C. J.; FARIA; R. T. Photosynthesis of individual leaves in a coffee plant. Acta Scientiarum Agronomy, Maringá-PR, v. 28, n. 3, p. 331-335, 2006. Disponível em: < http://periodicos.uem.br/ojs/index.php/ActaSciAgron/article/vi ewFile/941/470>. Acesso em: 10 janeiro 2017.

MATIELLO, J. B.; SANTINATO, R.; GARCIA, A. W. R.; ALMEIDA, S. R.; FERNANDES, D. R. Cultura do café no Brasil: manual de recomendações. Varginha-MG: SARC/PROCAFÉ, 2010. 548p.
OLIVEIRA, C. L. L. G.; MIGLIORANZA, E. Quality levels of organic coffee seedlings in black and white nonwoven fabric (NWF) containers of various sizes. African Journal of Agricultural Research, Nairóbi - Quênia, vol. 10, n. 9, p. 886-894, 2015. Disponível em: http://academicjournals.org/journal/AJAR/articleabstract/7EDED5550996>. Acesso em: 10 abril 2017 